\title{
Engineering of Complex Social Realities
}

\author{
German URREGO-GIRALDO ${ }^{\mathrm{a}, 1}$ Gloria-Lucia GIRALDO $^{\mathrm{b}}$ and Diana-Margot LÓPEZ ${ }^{\mathrm{a}}$ \\ ${ }^{\text {a }}$ Universidad de Antioquia \\ ${ }^{\mathrm{b}}$ Universidad Nacional de Colombia
}

\begin{abstract}
The creation and application of processes and resources realized by Engineering show important results in the exploitation of natural resources and in industry. Essentially, Engineering has been developed to satisfy the requirements of social agents but not to intervene in society itself. Artifacts produced by Engineering are used by society, but the elaboration of artifacts for managing directly society's own processes is not considered, in general, as an issue of Engineering. We introduce concepts of Supra Disciplinary Engineering aiming at Total Engineering and its central expression in Engineering for Society. It searches to offer methods of classical Engineering to intervene, together with those of social and human sciences, in own processes of society and human beings, considering empirical evidence, objective information, reasoning and the respect of fundamental rights of society, in a responsible relationship with the natural world.
\end{abstract}

Keywords. Supra Disciplinary Engineering, Total Engineering, Engineering for Society, Social Processes, Social Agents

\section{Introduction}

Since the primitive evolution periods, humans have had to exploit the resources of nature and face the effects of natural forces. Human survival and growth are linked to the capacity of adapting to and transforming the surrounding world. The discovery and use of procedures and resources to intervene in nature, based on knowledge acquired by observation and experience, constitute the birth of Engineering. Although the exercise of Engineering is ancient, this denomination is recent, as it appears in sources [1] and [2]. When humans think about the causes of events and phenomena and search deep in their understanding and explanation, beyond the experiences, new knowledge appears, giving shape to the concept of science. Indeed, a separation occurs between the knowledge experienced in life, the practical knowledge, and the scientific knowledge. This one encloses the scientific explanation based on principles inherent to the natural things, and agrees with Aristotle's ideal of science. This separation marks the beginning of science. At the birth of science, technology offers solutions based on science. Engineering receives knowledge coming from science and technology and amplifies the scope of its interventions.

In the Renaissance period, in the $15^{\text {th }}$ century, there was a vague definition of the profession of Engineer and there began, in this century, a generation of wise engineers who furthermore were familiar with physics and mathematics, astronomy, arts, and languages as described by Valencia, in source [3].

\footnotetext{
${ }^{1}$ Corresponding Author, Email: gaurrego015@gmail.com.
} 
At the end of the $16^{\text {th }}$ century, as the work of G. Hirsch Hadorn et al. shows in source [4], the foundations of theory supporting the experimental intervention on nature were established, giving place to a new concept of science in the modern epoch. These events determine the dissociation of natural science from philosophy and the intensification of studies leading to consolidate a scientific method. Aristotle in the antique era had formulated his inductive-deductive method, and many recognized scientists and philosophers contributed during centuries to the formulation of a method universally accepted in natural sciences. In this period of modern science, technology became the object of applied research for the realization of solutions based on scientific knowledge. Engineering is empowered by technological development and it may incorporate existing empirical, technological and scientific knowledge.

The creation of the liberal market economy in the 19th century and the use of natural science and technology in industrial production constituted a determinant factor in economic growth. This instrumental value assigned to scientific knowledge by economics and society became an external driving force to invest resources in the development of modern science and the improvement of its experimental, quantitative and mathematical methods.

The impulse of science and technology on the productions of goods, the emigration of populations to cities, and the creation of the concept of fabrics define a scenario in which a new economic model flowers. This occurs in a society undergoing deep changes without establishing a clear model for its development. The urgency of paying attention to increasing economic demands, and the idea consisting in that the economic productivity assures the welfare of society concentrate efforts in the economy, neglecting consolidation of a social organization and the strengthening of social agents' actions and interactions. The economy took control of society and this subordination is increasingly accentuated to the extent that the social agents endowed with economic functions overpower the other social agents.

The development of science and technology is driven by the economic interest of those social agents exercising economic functions. In this way, science, and technology turned aside from the ideal of creating welfare for society. Some critics regarding these deviations are expressed, among others, in source [5], and [6]. Engineering fed by science and technology grows as an important field of activity.

Another milestone in the evolution of the concepts of science was established by the excision of social and human science from philosophy in the $19^{\text {th }}$ century. Émile Durkheim defined sociology as the science of social facts [7]. Evolving in this work Auguste Compte [8] shaped sociology as a field of knowledge and introduced empirical and mathematical methods in the study of social processes. The division within science continued with the development of social science. Max Weber [9] related research in social sciences with demands of knowledge to solve societal problems.

Furthermore, the separation of natural, social and human science from philosophy, the application of the scientific method, the development of social and human science, and the increasing relationship of science with the production of goods favored the division of science into disciplines. In this trend of the division of science, and to avoid the dispersion of knowledge, the surges the concept of transdisciplinarity research, which was strengthened in the 20th century by the development of the general system theory proposed by Bertalanffy in Biology [10], and applied in many fields: Niklas Luhmann, for example, in source [11], extended the system theory to sociology, thereby developing aspects in Engineering like those treated by Norbert Wiener in cybernetics, [12]; von Neumann and 
Morgenstern, in game theory [13], and Shannon in information, [14]. This proximity stimulates the joint work of Engineering and social science.

The system theory appears as an abstract structural model of scientific knowledge facing the trend of the continuous fragmentation of knowledge and research into more and more specialized disciplines. This fragmentation in research, higher education, and social institutions entails the risk of not preventing the negative side effects for society. For this, Erich Jantsch [15] proposes innovation in social planning, considering the interaction of Government-Industry-University including the creation of an education-innovation system. He also conceived to arrange knowledge into hierarchical goal-oriented systems, for which he introduced the term Transdisciplinarity, considering the general system theory and organization theory, which indicate the study of organizations by the means of systems theory. In this direction, Kockelmans [16], refuses the circumscription of problem-oriented research to particular theoretical frameworks. He denominates cross-disciplinary as the type of research related to finding reasonable solutions to specific problems while transdisciplinary research is related to the development of a general framework from which problems may be identified and solved.

While looking to solve the difficulty of normal science to address the uncertainty and diversity of interest of social agents in development and application of scientific research, Funtowicz and Ravetz [17], introduced the concept of post-normal science. They consider that the involvement of communities and other social agents and mutual learning with science are required in the formulation and implementation of scientific policy. The intervention of science as an agent in the policy process stimulates the discussion about democratization and reflection of science. In this sense, Gibbons [18] compared this, that he named Mode 1 of knowledge production, based on the Newtonian conception that links science with goods production, with Mode 2 characterized by transdisciplinarity, heterogeneity, reflectivity, social accountability, and context- and user-dependency. Nowotny [19] emphasizes the mutual learning for what she called "socially robust knowledge". The dialogue and mutual learning among scientists and other societal agents involve science in the process of policy formulations and gives meaning and value to knowledge considered in solutions to societal problems.

The United Nations Conference on Environment and Development (UNCED) in Rio de Janeiro in 1992 and the World Summit on Sustainable Development held in Johannesburg in 2002 insist on the urgency of implementing the sustainable development model, remark on the importance of science in this purpose and the need of evolving research by the inclusion of other social agents and the promotion of mutual learning of science and life-world, as noted by Hirsch Hardon et al. [4]. In this sense, as Hirsch Hardon et al. argue [20], sustainable development becomes a way of conceiving the common good as the basic principle of national legislation in a complex world. This external driving of science from natural resources was equally exercised from social science, as Böhem et al. argue in the Finalization Theory [21]. Similarly, Krohn et al. [22] recognize the double character of science, as a resource and change agent. This direct involvement_of science as an agent in social processes uses technology and Engineering as its effective instruments to achieve concrete solutions to problems that surpass the boundaries, not only of disciplines but also of sciences. Technology and Engineering find in the concept of process their natural space to accomplish the results envisioned. The management of social processes is the present challenge of Science, Technology, and Engineering, in order to dialogue, learn and cooperate with each other to accomplish the objective of society. 
In this frame, we introduce the idea of Supra Disciplinary Engineering, which applies in social processes to constitute Engineering for society, and orients its efforts toward Total Engineering.

The remainder of this article contains in Section 1 the development of the Engineering Concept in Science. The own general processes of society and interacting social agents are described in Section 2. The way to implement Engineering for society is illustrated in Section 3. Conclusions and Future works are developed in Section 4. References constitute the last Section.

\section{Development of Engineering Concept in Science}

The short journey, in the Introduction, through the evolution of scientific knowledge and its relationship between science and life-world allows us to understand the diversification of knowledge disciplines and ways to tackle the study of reality as a whole. In this direction, some studies related to different ways of multidisciplinary, interdisciplinary, and transdisciplinary research are being elaborated, among others, by Nicolescu [23], Hirsch Hadron [4], Bernstein [24], and Mitchel [25]. In these subjects, important contributions to the Engineering field, are presented by Ertas [26], [27], Wognum et al. [28], and Del Cerro Santamaría [29]. The classification of Engineering in terms of the evolution of disciplinary knowledge and of the link between empirical and scientific knowledge provides a foundation for_Engineering that uses new knowledge of diverse fields. In this sense, Multidisciplinary Engineering realizes a process or a set of processes of a particular discipline or project, in order to accomplish its objectives, using processes or projects of other disciplines, each one, with its own methods. Interdisciplinary Engineering realizes processes or projects of diverse disciplines using their own methods, contributing to accomplishing objectives of a process, a set of processes, or a project of a particular discipline and to solve problems whose solutions are beyond the scope of this single discipline, under coordination of this one or a project, creating new knowledge, new applications, or new disciplines. Cross-disciplinary Engineering considers the solution of problems centered in a particular disciplinary process, a set of processes, or a project, using results (products) from processes of other disciplines. Cross-disciplinary Engineering concerns the realization of projects to accomplish goals of a particular discipline that require gathering studies and solutions of diverse knowledge fields or disciplines of knowledge affected by these projects. Transdisciplinary Engineering treats a process, a set of processes, or projects of diverse disciplines, using in a collaborative, interactive, and reflective way their own new or existing methods, involving internal and external agents, in order to accomplish their objectives and to solve problems, whose solutions are beyond the scope of these processes, or set of processes, or projects, belonging to the field of natural science and/or mathematics.

Cross-disciplinary Engineering is a product-centered approach, while the grasp of multidisciplinary, interdisciplinary, and transdisciplinary Engineering is process-centered.

The preceding types of Engineering were characterized by the use of disciplinary knowledge. These approaches intervene in internal and external processes of material or mathematic realities (objects), and processes where these realities (objects) are treated, using knowledge of any field of science, so as to satisfy the demands of individuals and society. The scope of these approaches ultimately surpasses the disciplinary boundaries. A necessary Engineering approach emerges today, the Supra disciplinary Engineering, which breaks the boundaries of science fields. Supra disciplinary Engineering involves approaches that intervene in internal and external processes of all realities (objects), and 
processes where these realities (objects) are treated cooperatively, using methods and knowledge of any field of science, oriented towards the concept of Total Engineering, to contribute to the integral progress of society, and human beings in harmony with nature; that means Engineering for the development of society. Total Engineering is an ideal of action in any field of knowledge, developing its methods, creating and using technics for the identification and intervention of processes, in a cooperative way with social agents and individuals aiming at the integral progress of society, and human beings in a responsible relationship with nature.

Engineering may offer its methods, means, and models for directly managing social and human processes and projects. These are formulated in terms of contexts determined by social agents' action and interaction, acting on structured domain knowledge, as treated in source [30]. Engineering cooperates with methods of social, human, natural, and ideal sciences in a supra disciplinary approach aiming at the concept of Total Engineering.

\section{Own General Processes of Society and Interacting Social Agents}

Aiming at the accomplishment of its high-level objectives, society executes processes in which social agents intervene. In our research, forty of own general processes, thirty-three social agents, and more than a hundred high-level social projects are defined. High level (framework) social projects are related to the general processes aiming at the accomplishment of the six high-level objectives of society. All these functional elements of a society in action are extracted from sociological literature, among others, from [8], [9], [11], and [15]. To explain the concept of Engineering for society, as an essential expression of Supra disciplinary Engineering aiming at Total Engineering, introduced in this article, we developed an approach leading to formulating and reducing processes manageable by society. This approach was applied in two high-level projects: "Creation and Implementation of a Public Education System for the Progress of the Society with Total Coverage and Inclusion" and "Construction and Strengthening of Peace in Society". Related aspects are treated in [31], [32], [33] and [34].

The accomplishment of high-level objectives of society is possible if it can manage, under its responsibility, its own general processes. A sample of these are depicted in Table 1.

Table 1. Own general social processes.

\begin{tabular}{|c|l|}
\hline \multicolumn{2}{|c|}{ GENERAL PROCESSES OF SOCIETY } \\
\hline 1 & $\begin{array}{l}\text { Support Social Integration, Human Development, Regional Services, and Welfare construction } \\
\text { for communities and people }\end{array}$ \\
\hline 2 & Operate according to the functions of the state and complying strictly the constitution \\
\hline 3 & Manage Public Creation and Difusion of Knowledge and Technologies \\
\hline 4 & Manage Private Creation and Difusion of Knowledge and Technologies \\
\hline 5 & Promove Informal Public Education: General, Academic, recreational or Laboral Education. \\
\hline 6 & Promove Informal Private Education: General, Academic, recreational or Laboral Education \\
\hline 7 & Develop Formal Public Education: Basic, Medium, Superior and Postgraduate Education \\
\hline 8 & Develop Formal Private Education: Basic, Medium, Superior and Postgraduate Education \\
\hline 9 & Lead Oficial Interaction with other Societies \\
\hline 10 & Effect Private Interaction with other Societies \\
\hline 11 & Offer Public Information and Communication Services \\
\hline 12 & Offer Private Information and Communication Services \\
\hline
\end{tabular}


The forty own general social processes identified in our study are disaggregated into smaller manageable processes, in the organizational context where interacting agents are persons and systems. High-level projects of society are referred to in these processes.

Social agents are responsible for the social, human, and natural development and for the construction and implementation of solutions, which society requires. Each individual general social process is performed by a sub-set of social agents, belonging to the set of thirty-three categories of social agents. An extract of these categories are, listed in Table 2.

Table 2. Social agents interacting own processes of society.

\begin{tabular}{|l|l|}
\hline \multicolumn{2}{|l|}{ Social Agents } \\
\hline 1 & Communities and Persons \\
\hline 2 & $\begin{array}{l}\text { Public Researchers and Developers of Science, Technology and Technic (including } \\
\text { Engineering and other Professions) }\end{array}$ \\
\hline 3 & $\begin{array}{l}\text { Private Researchers and Developers of Science, Technology and Technic (including } \\
\text { Engineering and other Professions) }\end{array}$ \\
\hline 4 & $\begin{array}{l}\text { Public Formal Education Institutions, Organizations, and Persons (including Engineering, } \\
\text { Other Professions) }\end{array}$ \\
\hline 5 & $\begin{array}{l}\text { Private Formal Education Institutions, Organizations, and Persons (including Engineering, } \\
\text { Other Professions) }\end{array}$ \\
\hline 6 & Public Informal Education Institutions, Organizations, and Persons \\
\hline 7 & Private Informal Education Institutions, Organizations, and Persons \\
\hline 8 & Public Entitiies for the Elboration and Management of Social Products and Services \\
\hline 18 & $\begin{array}{l}\text { Constitutionalists, Legislators and Social Thinker Agents interested in the Development and } \\
\text { Improvement of the Own Identity, and in the adoption of the adequated Government System } \\
\text { for the Society }\end{array}$ \\
\hline 19 & $\begin{array}{l}\text { Public Entities (including Engineering and other Professions) charged of the Use, } \\
\text { Exploitation, and Trasnformation of Natural Resources related to Soil, Water, and Air }\end{array}$ \\
\hline 29 & Non-Gevernmental organizations \\
\hline 30 & Public Financial Sector (Capital and Market) \\
\hline 31 & Private Financial Sector (Capital and Market) \\
\hline 32 & State and Government Institutions \\
\hline 33 & Oher External Societies \\
\hline
\end{tabular}

\section{The way for the Implementation of Engineering for Society}

Engineering may help in recognizing its own general processes of society and the interacting agents, the proposition of high level (framework) projects to attain the highest objectives, the elicitation of requirements of society, the identification of problems and goals to satisfy social requirements, and finally the establishment of processes in terms of social agents' actions and interactions to attain each formulated goal.

Here, we explain how to reach the formulation of manageable processes under the responsibility of social agents. This explanation is based on a high level (framework) project "Construction and strengthening of peace in Society" introduced in [31]. The procedure adopted is based on Non-Functional Requirements that have to accomplish a society because of a particularly high-level project, in this case a society living in peace. The use of Non-Functional Requirements and Goals are illustrated in [35]. 
A society living in peace was characterized by a general set of categories of quality features, and each general process of society was characterized with a particular sub-set of categories of quality features, selected from a set of general categories. The first process announced, among the forty general processes, Table 1, recognized in the life of human society is expressed as; Support Social Integration, Human Development, Regional Services, and Welfare Construction for Communities and People. The particular subset of quality feature categories, selected from the general set of quality feature categories contains the following categories: Integrity, Cohesion, Solidarity, Justice, Equity, Knowledge, Learning, Critical Thinking, Harmony, Governance, Freedom, Autonomy, and Tolerance.

We illustrate the methodological approach adopted to formulate the manageable processes in Figure 1, considering only one goal among the twenty-three goals proposed for the quality feature category denominated cohesion. This category is only one among thirteen categories of quality features belonging to the particular set characterizing the first general process, among forty processes recognized in the life of modern human society. Obtaining these twenty-three goals is explained in [31].

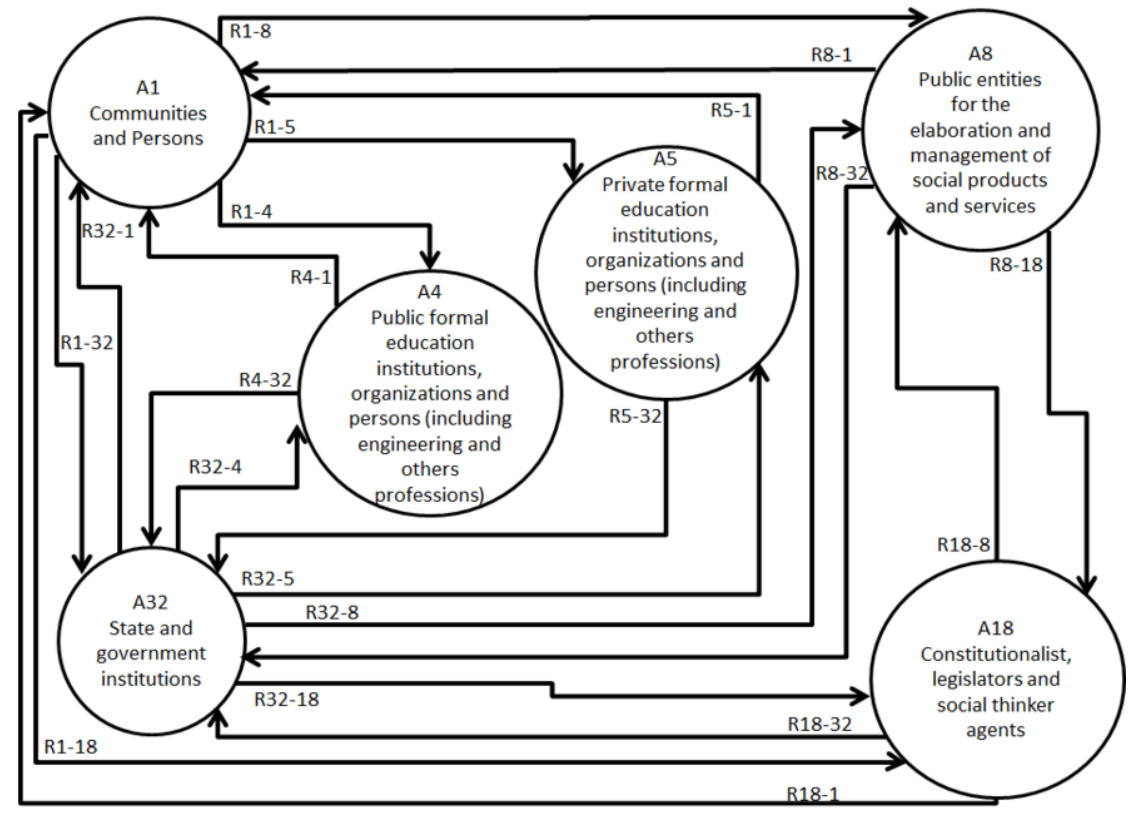

Figure 1. Context for Accomplishing the Goal Described.

From [31], six social agents interrelated in Figure 1 constitute a context to accomplish the goal: Establish that the ground, the subsoil, the water, the natural environment belong to society, and the owners keep the possession, use, and exploitation rights in the frame of respect to the social Rights.

The six social agents involved in the process to accomplish this goal are coded with A1, A4, A5, A8, A18, and A32 in the circles drawn in Figure 1. They belong to the set of 33 identified social agents, in Table 2, cooperating in the construction and conservation of peace. Table 3 depicts each one of the agents' interactions of these referred six agents, identified with the letter $\mathrm{R}$ and the codes of each couple of interacting agents. 
Table 3. Agents' interactions depicted in Figure 1.

GOAL: Establish that the ground, the subsoil, the water, the natural environment belong to the society, and the

R1-32 The Comunities and people demand to State and Government reincorporate in the Contitution the fundamental principle consisting of the ownwership of the Society over the land, air, water ans natural resources.

Government elaborates and processes a project leading to the restoration of the principle consisting of the

R32-1 ownership over the elements and resources provided by the nature and convene the communities and people to cooperte in the develoment of the project and in the implementation of its results.

Government convoke Constitutionalists and Social Thinkers to cooperate in the elaboration of a project leading

R32-18 to the restoration of the principle consisting of the ownership over the elements and resources provided by the nature.

R18-32 Constitutionalists and Social Thinkers elaborates and discuse with government the project.

R18-1 Constitutionalists and Social Thinkers uses collective work spaces and technological means to consult and discuss with the communities and the people elements of the project that is being developed.

R1-18 Communities and peoples promove the ample cooperation and give elements for the elaboration and development of the project.

Government formalize the inclusion in the Constitution of fundamental principle consisting of the ownwership

R32-8 of the Society over the land, air, water ans natural resources, and ask the Public Entitiies for the implementation of this principle in Social Products and Services.

R8-32 Public Entities manage the application of the ownweship principle and repport to the Government its accomplishment.

The communities and peoples demand to public entities the provision of services and resources in accordance with the principle of social ownership.

R8-1 Public entities promote and supervise the responsible cooperation of communities and people in the conservation and proper use of soil, water, air and other associated natural resources.

R8-18 Public entities request to Consitutionalists and Social Thinkers orientation and proposal of designing Social Products and Services.

Constitutionalists and Social Thinkers elaborate contributions obout Social Products and Services looking for the

R18-8 social, human, economic progress in harmony with the nature, and aid to Public Entities for the introduction of these contributions in the defintition of Products and Services.

Government demand to Public Formal Education Institutions, Organizations, and Persons (including Engineering

R32-4 and other Professions) to include, in their programmas and services, education activitivities and their direct contribution to developping in students and in their professional life the principle of social ownership.

Public Education Institutions, Organizations and Persons (including Engineering and other Professions)

implement, with their graduates communications nets presencial and remote meetings, in order to support the appliction of social ownership principle in the professional practice, and capitalize and repport to the Governments their realizations.

Government demand to Private Formal Education Institutions, Organizations, and Persons (including

R32-5 Engineering, and other Professions) to include, in their programms and services, education activitivities and their direct contirbution to developping in students and in professional life the principle of social ownership. Private Education Institutions, Organizations and Persons (including Engineering and other Professions) implement, with their graduates communications nets, presencial and remote meetings, in order to support the appliction of social ownership principle in the professional practice, and capitalize and repport to the Governments their realizations.

Public Eduacation Institutions, Organizations and Persons (including Engineering and other professions) coordinate with Communities and Persons the programming and realization of practices in these communties,

R4-1 as well as, the application of Social Ownership principle in the practices of Engineers and other professionals anywhere in the territory.

Communities and Persons cooperate with Public Eduacation Institutions, Organizations and Persons (including

R1-4 Engineering and other Professions) in the application of social ownership principle in projects of Engineers and other Professionals and in the realization of professional practices anywhere in the territory.

Private Eduacation Institutions, Organizations and Persons (including Engineering and other professions)

R5-1 coordinate with Communities and Persons the programming and realization of practices in these communties, as well as, the application of Social Ownership principle in the practices of Engineers and other professionals anywhere in the territory.

Communities and Persons cooperate with Private Eduacation Institutions, Organizations and Persons (including 
Management of the complete set of general processes and the entire set of social agents is the subject of other studies that are not included here for want of space. For the same reason in this section the twenty-three goals associated with the first general social process, announced above, do not appear. The goal selected for the example is very sensible in a society where the ownership of land has traditionally been an element of power. The easy way to reach the goal, respecting the rights of the owners and the fundamental rights of society, as it is shown by Engineering, indicates that social conflicts are due only to the irrational conduct of the social agents involved.

\section{Conclusion and Future Work}

The concept of supra-Engineering introduced, oriented towards total-Engineering, allows the coordinated intervention of complex social, human and natural realities, subjected to fundamental society's rights. The cooperative work of social agents may meet their individual goals without infringing upon anyone's rights and those of the society as a whole. The development of Framework Projects centered on its own society's processes leads to the achievement of superior society's states and to a glimpse of the idea of progress of society.

The application of engineering methods in social and human complex realities shows that solutions are possible and easy to obtain whenever every social agent respects the fundamental rights of the society and the rights of the other agents. Methods, models, and experiences of the supra-disciplinary Engineering approach may also support the collective work for the solution of problems in communities and organizations.

In the frame of Engineering for society, ongoing studies consider the formulation of processes for the creation and implementation of a public universal education system with total coverage.

\section{References}

[1] T. Tredgold, A Practical Essay on the Strength of Cast Iron, Taylor, London, 1822.

[2] D. Hill, A History of Engineering in Classical and Medieval Times. Routledge, London. 1997.

[3] A Valencia Giraldo, La evolución de la culture material: Una historia de la ingniería. Universidad de Antioquia, Medellín. 2005.

[4] G. Hirsch Hadorn, S. Biber-Klemm, W. Grossenbacher-Mansuy, H. Hoffmann-Riem, D. Joye, Ch. Pohl, U. Wiesmann, E. Zemp The Emergence of Transdisciplinary as a Form of Research. In G. Hirsch Hadorn et al. (eds.) Handbook of Transdisciplinary Research, Springer Verlag, Bern, pp. 19-42. 2008.

[5] J. Sanmartín, Tecnlogía y Futuro Humano, Anthropos, Barcelona, 1990.

[6] M. Medina and T. Kwiatkowska, Ciencia-Tecnología-Cultura. Anthropos, Barcelona, 2000.

[7] E. Durkheim, Les règles de la méthode sociologique.Librairie, Septieme Edition. Félix Alcan. Paris, 1919.

[8] A. Comte. A General View of Positivism. (Tr.) J.H.Bridges. Trubner and Co. 1865 (reissued by Cambridge University Press ISBN 978-1-108-00064-2). 2009.

[9] M. Weber, The Methodology of the Social Sciences (E.A. Shils and H.A. Finch, trans.). The Free Press, New York, 1949.

[10] L. von Bertalanffy, General system theory: foundations, development, applications, George Braziller, New York, 1968.

[11] N. Luhmann, Social Systems, Stanford University Press. Boston, 1995.

[12] N. Wiener, Cybernetics, Wiley, New York, 1968.

[13] J. von Neumann, O. Morgenstern. Theory of Games and Economic Behavior, Princeton University Press, Princeton, 1944.

[14] C.E Shannon. A Mathematical Theory of Communication, Bell System Technical Journal, 27, pp. 379-423 \& 623-656, July \& October 1948. 
[15] E. Jantsch, 1972, Towards Interdisciplinarity and Transdisciplinarity in Education and Innovation. (eds.): L. Apostel et al., in Problems of Teaching and Research in Universities, Organisation for Economic Cooperation and Development (OECD) and Center for Educational Research and Innovation (CERI), Paris, pp. 97-121.

[16] J.J. Kockelmans. Why Interdisciplinarity? In: J.J. Kockelmans (ed.) Interdisciplinarity and Higher Education, The Pennsylvania State University Press, University Park and London, pp. 125-160. 1979.

[17] S.O. Funtowicz, J.R, Ravetz. Science for the Post-Normal Age, Futures, 25, 739-755. 1993

[18] M. Gibbons, C. Limoge, H. Nowotny, S. Schwartzman, P. Scott and P. Trow. The New Production of Knowledge. The Dynamics of Science and Research in Contemporary Societies, Sage Publications, London, 1994.

[19] H. Nowotny. The Need for Socially Robust Knowledge, TA-Datenbank-Nachrichten, 8, 12-16. 1999.

[20] G. Hirsch Hadorn, D. Bradley, C. Pohl, S. Rist, and U.Wiesmann, Implications of Transdisciplinarity for Sustainability Research, Ecol Econ 60, 119-128. 2006

[21] G. Böhme, W. van den Daele, R. Hohlfeld, W. Krohn, and W. Schäfer: Finalization in Science: The Social Orientation of Scientific Progress (P. Burgess, trans.), Reidel, Dordrecht, 1983.

[22] W. Krohn. and W. van den Daele, Science as an Agent of Change: Finalization and Experimental. Implementation, Soc Sci Inform, 1998, 37, 191-222.

[23] B. Nicolescu. La Transdisciplinarité - Manifeste, Éditions du Rocher Monaco, 1996. Retrieved November 1, 2006, from www.nicol.club.fr/ciret/english/visionen.htm.

[24] J. H. Bernstein. Transdisciplinarity: A review of its origins, development, and current issues. Journal of Research Practice, 11(1), Article R1. 2015. http://jrp.icaap.org/index.php/jrp/article/view/510/412

[25] C. Mitchell, D. Cordell and D. Fam. Beginning at the end: the outcome spaces framework to guide purposive transdisciplinary research, Futures, 2015,Vol. 65, pp. 86-96.

[26] A. Ertas, M. Tanik, T. Murat and T. Maxwell, Transdisciplinary Engineering Education And Research Model. Transactions of the SDPS, Vol. 4, No. 4, pp. 1-11. 2000.

[27] A. Ertas. Understanding transdiscipline and transdisciplinary process. Transdiscipl. J. Engin. Science, Vol. 1, No. 1, pp.55-73. 2010

[28] N. Wognum, C. Bil, F. Elgh, M. Peruzzini, J. Stjepandic and W. Verhagen. Transdisciplinary systems engineering Implications, challenges and research agenda. International Journal of Agile Systems and Management. 12. 58. 10.1504/IJASM.2019.098728. 2019.

[29] G. del Cerro Santamaría, Towards Transdisciplinary Urbanism: Megaprojects, Power and the Urban Imagination. Transdisciplinary Journal of Engineering \& Science, Vol. 9, pp. 23-36, 2018.

[30] G. Urrego-Giraldo, G.L. Giraldo G., Differentiated Contribution of Context and Domain Knowledge to Products Lines Development, Advances in Transdisciplinary Engineering, IOS Press, Amsterdam, 2014, pp. $239-248$.

[31] G. Urrego-Giraldo, G.L. Giraldo G., Quality Features-Based Model of Interactions of Engineers and Meaningful Social Agents for Contributing to the Construction of Social Peace, Weef Conference. Albuquerque. 2018. https://weef-gedc2018.org/wp-content/uploads/2018/11/215_Quality-Features-BasedModel-of-Interactions-of-Engineers-and-Meaningful-Social-Agents-for-Contributing-to-the-Cons.pdf

[32] P.A. Vesilind. The Evolution of Peace Engineering. In: P.A. Vesilind and W.R. Bowen (eds.) Peace Engineering: When Personal Values and Engineering Careers Converge, Lakeshore Press, Woodsville. 2013.

[33] W. R. Bowen. From Ghosts Behind the Machines to Just Engineers: How Engineering Can Promote Peace. In: P.A. Vesilind and W.R. Bowen (eds.) Peace Engineering: When Personal Values and Engineering Careers Converge, Lakeshore Press, Woodsville, 2013.

[34] W.R. Bowen, Engineering Ethics. Challenges and Opportunities, Springer, Cham, 2014.

[35] G. Urrego-Giraldo, G. L. Giraldo, E. Córdova, Accomplishing of Quality-Based Objectives of Social Integration and Regionalization in Minerva Academic Model. 2015 International Conference on Interactive Collaborative Learning (ICL), 2015, DOI: 10.1109/ICL.2015.7318100. 